\title{
A comparison of clinical trial and model-based cost estimates in glaucoma - The case of repeat laser trabeculoplasty In Ontario
}

\author{
A. Omar Akhtar ${ }^{1}$, Janet Martin ${ }^{1}$, Greg S. Zaric ${ }^{2}$, Francie Si ${ }^{3}$, Cindy M.L. Hutnik ${ }^{3}$, William G. Hodge*1,3 \\ ${ }^{1}$ Dept. of Epidemiology \& Biostatistics, Western University, London, Ontario, Canada \\ ${ }^{2}$ Richard Ivey School of Business, Western University, London, Ontario, Canada \\ ${ }^{3}$ Dept. of Ophthalmology, Western University, London, Ontario, Canada
}

Received: March 7, 2016

DOI: $10.5430 /$ jha.v6n3p46
Accepted: March 6, 2017

URL: https://doi.org/10.5430/jha.v6n3p46
Online Published: May 16, 2017

\begin{abstract}
Economic evaluations of glaucoma interventions require accurate costs in addition to effectiveness data. However, the impact of different costing methods on cost estimates has not been investigated. Direct cost estimates alongside clinical trials may be labour-intensive and expensive, modelled cost using literature sources and institutional experience may be an alternative. We investigated modeled and directly collected costs of a trial comparing argon- and selective-laser trabeculoplasty (ALT and SLT) among glaucoma patients at St. Joseph's Health Care in London, ON between 2013 and 2014, also comparing ministry and societal perspectives and cost drivers. Model and trial cost estimates differed minimally for the ministry perspective $(8 \%$ and $4 \%$ for ALT and SLT) despite differences in modeled and observed parameter values and treatment pathways. Labour accounted for $90 \%$ of total cost. Costs were similar for the societal perspective although there was sensitivity to assumptions regarding patient time loss. Indirect costs were at least as large as direct medical costs. Modeled costs were an acceptable substitute for directly measured costs in this scenario.
\end{abstract}

Key Words: Economic evaluation, Microcosting, Glaucoma laser treatment, Cost-effectiveness analysis, Indirect costs, Decision models

\section{INTRODUCTION}

\subsection{The use of lasers in glaucoma}

The use of lasers is most often situated between medication and surgery in the treatment of glaucoma. The general principle underlying laser trabeculoplasty is to alter the trabecular meshwork and thereby induce structural or functional changes which permit increased outflow of aqueous humour.

Selective-laser trabeculoplasty (SLT) acts as a "cold laser" due to its use of lower energy pulses and shorter bursts than argon-laser trabeculoplasty (ALT). This was found to produce equally effective intra ocular pressure (IOP) reduction, but without the major histological damage of ALT. The precise mechanisms by which SLT reduces IOP are not fully understood, but it is thought to induce a suite of biological mechanisms that act to augment trabecular outflow, as opposed to the putatively mechanical effects of ALT. ${ }^{[1]}$

A consequence of SLT's non-destructive mechanism of action is that it is, in theory, repeatable. If so, its utility is

\footnotetext{
${ }^{*}$ Correspondence: William G. Hodge; Email: William.Hodge@sjhc.london.on.ca; Address: Ivey Eye Institute, Schulich School of Medicine, Western University, St. Joseph's Hospital, 268 Grosvenor Street, London, Ontario N6A 4V2, Canada.
} 
considerable. Determining the repeatability of SLT and its interaction with other treatment elements is of paramount importance for determining the optimal treatment of glaucoma

\subsection{A brief overview of costing in economic evaluations}

Rising healthcare costs mean that decision-makers want to provide the same quality of care or better while minimizing costs. Cost-effectiveness analyses and cost-utility analyses (both subsumed under the former term, henceforth CEAs) are the most common forms of economic evaluation. A CEA often compares two interventions $\mathrm{X}$ and $\mathrm{Y}$, where $\mathrm{Y}$ produces better clinical effect (whether decreases in morbidity or mortality) but at higher cost. The final measure of interest is the incremental cost-effectiveness ratio or ICER, calculated as the difference in effectiveness divided by the difference in cost. $^{[2]}$ This represents the cost per additional unit of health effect.

Unsurprisingly, to be useful to decision makers, CEAs require relevant, transparent and accurate cost and effectiveness data. Effectiveness data is at least as important, but we will be focusing on costs in this paper. Costs remain understudied relative to effectiveness ${ }^{[3]}$ and the lack of transparent, accurate cost data impacts the validity of CEAs and may lead to inappropriate reimbursement decisions, as well as preventing their use at a level commensurate with their promise. ${ }^{[4,5]}$

The cost and effectiveness data for CEAs may be obtained in two ways: ${ }^{[6]}$ Dollar by dollar alongside a clinical trial (or population-based study)-often called microcosting. Alternatively, a synthesis of literature-based sources (and institutional experience, expert opinion and assumptions where these are unavailable) may provide relevant figures to populate a decision-analytic model such as a decision tree or Markov model-often called gross or macrocosting.

\subsection{Microcosting vs. gross costing methods}

Microcosting approaches measure and cost out the individual components of resource use in providing a service (e.g. physician and nurse time, disposables and other relevant cost categories). ${ }^{[7]}$ Microcosting is considered to be the closest thing to a "gold standard" in costing ${ }^{[8,9]}$ and is thought to represent the most accurate approach to costing. Given the difficulties associated with direct microcosting measurements, analysts are interested in finding easier methods of cost estimation that are still valid. ${ }^{[10]}$ One such method is the use of modelling in place of direct costing. Gross-costing modelling approaches comprise a number of methods that charge at a more highly-aggregated level of service provision (e.g. charging per day of inpatient stay or episode of care based on diagnosis - as opposed to enumerating and costing the resources that are used in providing the episode). The choice between microcosting and gross costing methods is often framed as a trade-off between accuracy and ease of data collection, with microcosting approaches offering better accuracy but being more difficult to undertake. ${ }^{[11]}$

Because of the many advantages of decision-analytic modelling, ${ }^{[9]}$ modelled costs remain the preferred method in health economics but such costs are rarely validated. In this paper, we assess the validity of a gross costing method for repeat laser trabeculoplasty for glaucoma by comparing these modelled gross costs to measured microcosting methods that we measure alongside an pragmatic randomized clinical trial comparing SLT and ALT among patients who have previously received SLT.

\section{METHODS}

\subsection{Objectives}

To assess the extent to which clinical trial and model-based costs agree for repeat laser trabeculoplasty. In doing so we examine whether modelled costs provide an acceptable substitute for microcosting and attempt to validate the sort of modelled costs found widely in CEAs.

Secondary objectives are to assess the impact of indirect and travel costs to overall cost estimates and thus the difference in total costs between the Ministry and societal perspective. Finally, to assess sensitivity of the decision-analytic model to a variety of assumptions and scenarios, thereby identifying main drivers of costs and overall robustness of the model.

\subsection{Intervention to be costed}

The application of laser trabeculoplasty after previous 360 degrees of SLT plus a schedule of 6 follow-up visits are performed over the course of a year. Unscheduled followup visits, adjunct medications and progression to incisional surgery represent deviations from normal care and will count as additional costs. A more detailed description follows in section 2.6 below.

\subsection{Overview of microcosting and gross costing methods}

In microcosting we arrive at a total cost estimate for each patient in the clinical trial. This is done through obtaining values from data record forms, patient charts, interviews with personnel and a patient questionnaire. These patient specific cost estimates are used to calculate a mean cost per patient for each laser modality. In model-based costing a decision tree based on a mixture of literature, institutional experience and expert opinion estimates is used to derive expected cost per patient. 


\subsection{Final outcome measures}

Each method produces a mean dollar value per patient, valued in 2014 Canadian dollars. The metric of interest is the disparity between micro and model based cost estimates within a technology (e.g. difference between average trial and modelled costs for SLT). The perspective for the reference case is that of the Ontario Ministry of Health and Long-Term Care (henceforth the Ministry) as per CADTH guidelines. ${ }^{[12]}$ The societal perspective will be presented as a secondary perspective of interest.

\subsection{Description of trial}

The Repeat SLT study is a multi-centre effectiveness trial assessing the effects of repeat laser trabeculoplasty (SLT or ALT) after previous SLT. The present study only considers data from the London Ontario site.

The RCT received approval from The University of Western Ontario Health Science Research Ethics Board (REB\# - 103028). The addition of a patient cost questionnaire for this economic sub-study received REB approval as an amendment. Further trial details are available at https: //clinicaltrials.gov/ct2/show/NCT01687465.

\subsection{Intervention structure and cost components}

The intervention may thus be conceptualized of as 1 laser surgical visit and 6 follow-up visits consisting of a partial assessment and IOP check. Because one such visit occurs at 1 hour post-laser, we may alternatively use the idea of 6 discrete visits, one of which is the laser and 1 hour follow-up. An ophthalmologist is present at all visits and an ophthalmic technician provides assistance and reads intraocular pressures from the tonometer. There are no disposables used except for a drop of brimonidine post-laser. Unscheduled visits, adverse events or changes in medication are available from patient charts - these represent additional costs incurred beyond the normal course of treatment. Patient travel time and lost productivity is captured via questionnaire. Table 1 displays the expected clinical pathway in tabular form and provides a list of resource categories to consider. In particular, this schedule of laser and prescribed follow-ups is assumed to be normal clinical care and will be the default pathway in the decision-analytic model, relative to which all deviations occur.

\subsection{Model section}

A decision tree was used to represent the possible clinical pathways that a patient would follow over the course a year, their probabilities and associated costs.

In the initial model (the base tree), patients started either medicated or unmedicated (ProbMed) which was set to 0.8 in consultation with physicians. Initial medication was assumed to consist of generic latanoprost. Patients were further stratified by whether they were older than 65 or not (Prob65), set to 0.6 in the model reflecting NIH data on glaucoma patient age. Trabeculoplasty could be successful or unsuccessful (ProbSucc), set to 0.7 reflecting available literature. Patients who were unsuccessful were assumed to either require additional medication or incisional surgery.

A second model (augmented tree) was developed to examine structural uncertainty. In this model after failure of trabeculoplasty all patients were assumed to require a second medication, which could either succeed or fail. Upon failure patients could either take a third medication or proceed to surgery.

Table 1. Structure of intervention, constituent visits and their required resources

\begin{tabular}{|c|c|}
\hline Node in clinical pathway of repeat laser trabeculoplasty & Resources consumed \\
\hline $\begin{array}{l}\text { First visit - laser treatment and follow-up at } 1 \text { hour to check } \\
\text { for adverse events }\end{array}$ & $\begin{array}{l}\text { Personnel (physician and ophthalmic tech time - laser treatment), } \\
\text { drops of Brimonidine, capital costs of laser, patient costs (travel } \\
\text { costs and parking, informal caregiving, lost time), Maxidex ( } 4 \text { drops } \\
4 x / d) \text {, any other medications. }\end{array}$ \\
\hline 1-hour follow-up & $\begin{array}{l}\text { Personnel (partial assessment and tonometry, tech time), patient } \\
\text { costs, changes in medication. }\end{array}$ \\
\hline 1 week follow-up & Repeat as above \\
\hline 1 month follow-up & Repeat \\
\hline 3 month follow-up & Repeat \\
\hline 6 month follow-up & Repeat \\
\hline $\begin{array}{l}1 \text { year follow-up } \\
\text { - Unscheduled follow-ups and complications } \\
\text { - Only for model, unlikely to be observed during trial - } \\
\text { incisional surgery (trabeculectomy). }\end{array}$ & $\begin{array}{l}\text { Repeat } \\
\text { Additional personnel costs, patient costs, medication. } \\
\text { Personnel costs (physician, nurses, anaesthetist), medications } \\
\text { (Ocuflox antibiotic, prednisolone) }\end{array}$ \\
\hline
\end{tabular}


Additional details on parameter derivation and data sources are available at http://ir.lib.uwo.ca/cgi/viewcont ent . cgi?article=4165\&context=etd. The tree was implemented in TreeAge $R$.

\subsection{The treatment of direct costs \\ 2.8.1 Labour - Physician time}

Physician time was required for initial performance of laser surgery, follow-up visits consisting of partial assessment and tonometry at 1 hour, 1 week and 1, 3, 6 and 12 months post-laser for a total of 1 laser appointment and 6 scheduled follow-ups.

Unscheduled visits may occur due to uncontrolled IOP and have the same fee as the scheduled follow-up visits. Physician fees were obtained from the Ontario Health Insurance Plan Schedule of Benefits. While not yet observed during the trial, for the model it was assumed that patients may progress to trabeculectomy within the one-year post laser based on previous reports ${ }^{[13,14]}$ and institutional experience.

\subsubsection{Labour - Ophthalmic technician time and nurse time}

An ophthalmic technician was present with the ophthalmologist to perform tonometry and other procedures. For the surgery scenario in the model, it was assumed that two hours of nurse time would be needed, comprising the one hour of surgery and involving two nurses.

\subsubsection{Capital costs}

Capital costs reflect expenditures on the equipment needed to provide the intervention. Specific values can be found in Table 2.

\subsubsection{Medications}

It is in the treatment of medications that trial and model diverge and that the ministry and societal perspectives differ. While in the trial there is individual patient-level data on actual use of medications, in the model we assume the most commonly observed procession of medications. ${ }^{[15,16]}$ Furthermore, for the ministry perspective, only drugs on the formulary are considered, and then only for those on the Ontario Drug Benefit (ODB) plan, comprising seniors 65+ and low-income persons. For the societal perspective, all drugs are considered regardless of their formulary status and the patient's ODB status. In the trial the patient's age is available to indicate ODB status. In the model the $65 \pm$ distribution is modelled based on figures from the NIH and Statistics Canada.

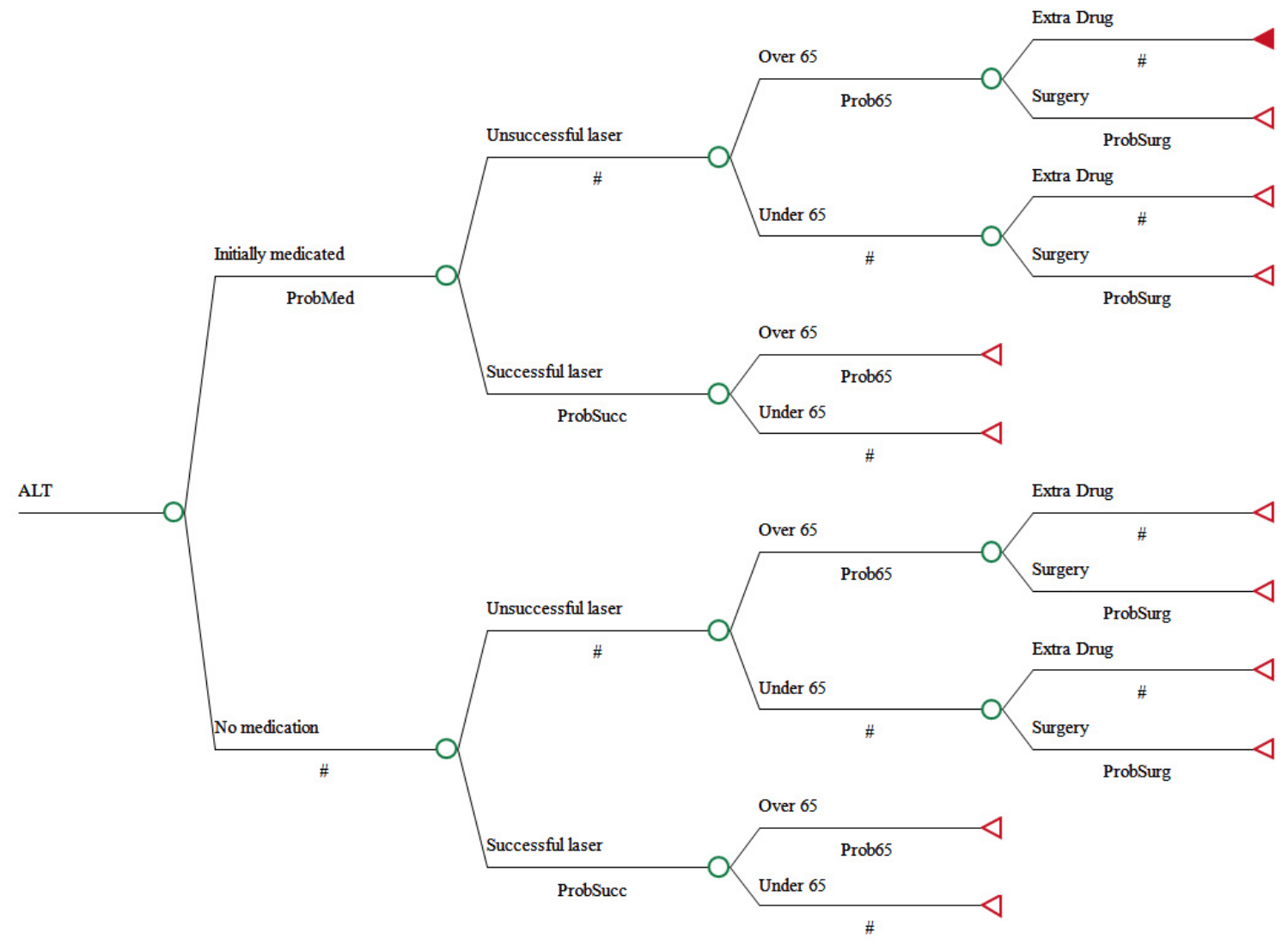

Figure 1. Base tree model - ALT 


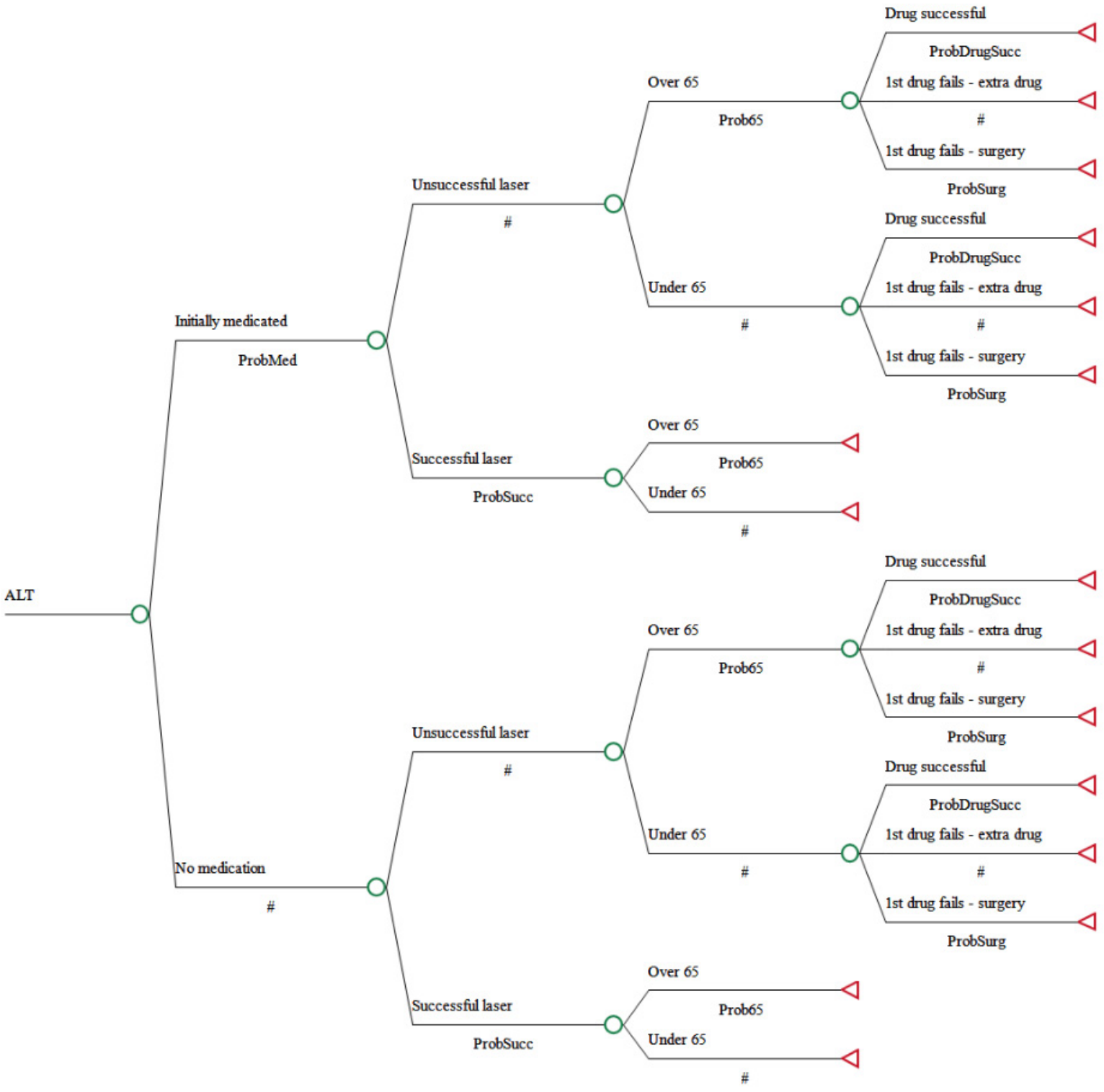

Figure 2. Augmented tree model - ALT

There are medications which all patients receive as part of treatment - brimonidine post-laser (which is included in capital costs, as the hospital provides it), and a prescription for dexamethasone ( $4 \mathrm{x} /$ day for 4 days). There is variability in whether or not patients start the trial on medications or not. This is recorded directly in the trial costing. In the model the percentage starting on medications is defined by the parameter ProbMed. Assumptions regarding the sequence of medications is available at http://ir.lib.uwo.ca/cgi/view content. cgi ?article $=4165 \&$ context=etd. Unit costs are derived from the Ontario formulary.

It is assumed that patients are prescribed generics where available and that patients are prescribed the minimum commercially available volume for each prescription (considering the limited lifetime of some ophthalmic medications, ${ }^{[17]}$ and the need for regular visits, it's unlikely that large volumes will be prescribed at any one visit). In the event of multiple medications, it is assumed that all medications are put onto one prescription and refilled at the rate of the medication that needs to be refilled most frequently. It was assumed that all medications were taken unilaterally, as was laser.

\subsubsection{Perspectival issues for drug costs}

This is an item on which perspectives diverge. From the ministry perspective, all drugs given in hospital and all drugs issued to patients on the ODB are costs. Thus drugs that are not on the formulary or those given to patients under 65 are not costs - they are covered by private insurance or out-of-pocket payments. 
Table 2. Capital cost calculations

\begin{tabular}{lll}
\hline Cost item & ALT & SLT \\
\hline Laser (L) & $\$ 180,000$ & $\$ 70,000$ \\
Tube replacement (TR) & $\$ 25,000$ & N/A \\
Exam chair (EC) & $\$ 5,000$ & $\$ 5,000$ \\
Service contract (SC) & $\$ 8,800 /$ year & $\$ 5,085 /$ year \\
Lens replacement (LR) & $\$ 500 /$ year & $\$ 500 /$ year \\
Medications/supplies per patient (MS) & $\$ 1 /$ patient & $\$ 1 /$ patient \\
Lifetime of laser (Y) & 8 years & 8 years \\
Number of patients per year (N) & 1,000 & 500 \\
Cost per patient & $\$ 36.56$ & $\$ 30.92$ \\
\hline Note. Unit cost $-\$ 36.56$ for ALT, $\$ 30.92$ for SLT, derived according to the \\
following calculation: & \\
Per patient capital cost = & \\
& &
\end{tabular}

For the societal perspective, the costs of all drugs are included regardless of patient age. A $10 \%$ pharmacy markup is assumed as is a full $\$ 6.11$ for those 65 and older (representing ministry payment of dispensing fee $+\$ 2$ ODB patient co-payment) copayment for ODB patients. The price of drugs for those not on ODB is assumed to be the same price as on the formulary with the $10 \%$ markup.

\subsubsection{Costs not considered}

Administrative time was not considered as it was assumed to be minimal. The costs of buildings, overheads and infras- tructure other than the laser equipment were not counted. These costs are difficult to ascertain and assigning them to specific procedures suffers from an irreducible arbitrariness and sensitivity to methods. ${ }^{[4,18,19]}$

\subsection{Sensitivity analyses}

The following parameters were varied in sensitivity analyses: ProbMed (probability of being initially medicated), Prob65 (\% of cohort aged 65+), ProbSucc (probability of laser success) and ProbSurg (probability of proceeding to surgery upon failing laser).

\section{RESUlts}

\subsection{Ministry perspective}

Data was available for 16 participants in total. Demographic characteristics are listed in Table 3 as are trial-derived costs in Table 4. Tables 5 and 6 provide results from the model and sensitivity analyses. Table 7 examines the performance of the augmented model. Figures 3 and 4 consist of a tornado diagram showing relative sensitivity to key parameters and an examination of patient volume effects on expected costs, respectively. Finally, Table 8 compares overall structure and parameter values from the model and trial.

Table 3. Trial patient demographic characteristics

\begin{tabular}{lll}
\hline Characteristic & ALT $(\boldsymbol{n}=\mathbf{8})$ & SLT $(\boldsymbol{n}=\mathbf{8})$ \\
\hline Average Age $( \pm S D)$ & $67.8( \pm 6.8)$ & $63.7( \pm 9.7)$ \\
Male/Female & $5 \mathrm{M}, 3 \mathrm{~F}$ & $4 \mathrm{M}, 4 \mathrm{~F}$ \\
Number starting on medication & $1 / 8$ & $2 / 8$ \\
Complications and additional medication & 1 pt. with extra follow-up visit and medication & No complications \\
Right/Left Eye & $6 / 2$ & $5 / 3$ \\
\hline
\end{tabular}

Table 4. Trial-based costing, ministry perspective

\begin{tabular}{|c|c|c|c|c|}
\hline Cost category $^{\S}$ & $\operatorname{ALT}(n=8)$ & SLT $(n=8)$ & ALT \% of Total & SLT \% of Total \\
\hline \multicolumn{5}{|l|}{ Laser visit } \\
\hline - Personnel $^{f}$ & $225.55(0)$ & $225.55(0)$ & & \\
\hline - Capital & $36.56(0)$ & $30.92(0)$ & $6.93 \%$ & $5.73 \%$ \\
\hline \multicolumn{5}{|l|}{ Follow-up visits } \\
\hline Personnel & $249.3(22.21)$ & $249.3(0)$ & & \\
\hline - Personnel total - physician & $409.85(18.20)$ & $409.85(0)$ & $77.66 \%$ & $75.96 \%$ \\
\hline - Personnel total - tech & $65(4.01)$ & $65(0)$ & $12.32 \%$ & $12.05 \%$ \\
\hline - Personnel total - total & $474.85(22.21)$ & $474.85(0)$ & $89.98 \%$ & $88.0 \%$ \\
\hline Drugs & $16.34(30.76)$ & $33.81(85.06)$ & $3.10 \%$ & $6.27 \%$ \\
\hline Total cost, ministry perspective & $527.75(37.94)$ & $539.58(85.06)$ & & \\
\hline Min, $\max$ & $469.86,602.11$ & $505.77,749.55$ & & \\
\hline
\end{tabular}

Note. ${ }^{\S}$ All costs in 2014 Canadian dollars; ${ }^{£}$ Consisting of physician and ophthalmic technician time

\subsection{Societal perspective}

Seven participants in the SLT arm and six participants in the ALT arm provided information on indirect costs. Obtained values for patient time use, accompanying persons Published by Sciedu Press and transportation are listed in Table 9. Trial-based estimates of societal costs are in Table 10. Table 11 presents results from modelling of societal costs and Figure 5 shows sensitivity to key parameters in the societal model. 
Table 5. Model-based costs, ministry perspective (2014 Canadian dollars)

\begin{tabular}{lll}
\hline & ALT & SLT \\
\hline Expected value & 568.52 & 562.88 \\
Min, max & $491.41,1,259.86$ & $485.77,1,254.22$ \\
Univariate Sensitivity Analyses: & & \\
- Prob65 (30\%-90\%) & $546.12,590.92$ & $540.48,585.28$ \\
- ProbSuccess (30\%-80\%) & $616.41,556.55$ & $610.77,550.91$ \\
- ProbMed (unmedicated-80\% initial medication) & $538.01,568.52$ & $532.37,562.88$ \\
- ProbSurg (0\%-40\% of those whose laser failed) & $549.27-626.27^{\varphi}$ & $543.63,620.63$ \\
\hline
\end{tabular}

Note. ${ }^{\varphi}$ Bolded entries result in over $10 \%$ deviation from initial expected value

Table 6. Ministry perspective, scenario analyses that caused $>10 \%$ deviation from expected value

\begin{tabular}{|c|c|c|}
\hline & $\mathbf{A L T}$ & SLT \\
\hline Bivariate 1: Low success, older cohort & 641.22 & 635.58 \\
\hline Bivariate 2: High progression to surgery, older cohort & 647.78 & 642.14 \\
\hline Bivariate 3: Low success, high rates of surgery & 751.16 & 745.52 \\
\hline Bivariate 4: Highly medicated, highly surgeried & 626.27 & 620.63 \\
\hline Trivariate $2^{\xi}$ : Old, unsuccessful, surgery & 773.88 & 768.24 \\
\hline
\end{tabular}

Note. ${ }^{\xi}$ All trivariate sensitivity analyses including ProbMed reduce to the bivariate case because the uppermost value of ProbMed is the same as the value in the base tree

\section{Discussion}

\subsection{The ministry perspective}

From the ministry perspective, the microcosting and model estimates did not differ appreciably (ALT: $\$ 527.75$ vs. $\$ 568.52$ - 8\% difference, SLT: $\$ 539.58$ vs. $\$ 562.88-4 \%$ difference). Labour accounted for the vast majority of costs, comprising almost $90 \%$ of total costs. Physician fees alone accounted for nearly $80 \%$ of total costs - drugs and capital expenses accounted for slightly more than $10 \%$ of total costs in both cases.

We note that the model and micro estimates closely agreed even though they look very different in their structure and parameters. Firstly, while $80 \%$ of model patients began on medication, less than $20 \%$ of trial participants did. Secondly, not a single trial participant underwent the sequence of medications that obtained in the model. Thirdly, there was no surgery observed in the trial. Fourth, the rate of failure in the trial was far less than assumed in the model. If the trial was structured as a decision tree, it would differ in both structure (lacking a surgery arm) and parameter values from the model we produced.

Table 7. Augmented tree model, expected value and sensitivity analyses

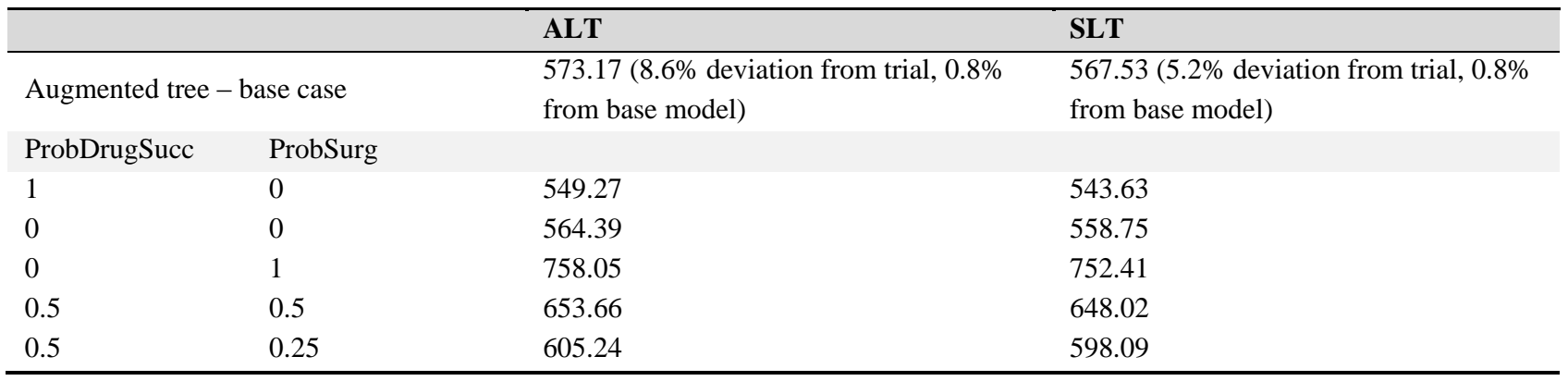

Table 8. Comparison of model (base tree) and trial parameters and characteristics

\begin{tabular}{llll}
\hline Variable & ALT Trial & SLT Trial & Model \\
\hline Percent medicated & $12.5 \%$ & $25 \%$ & $80 \%$ (reference case) \\
Types of adjunctive & Co-Dorzotimolol (1 patient & Latanoprost, Co-Dorzotimolol, & Latanoprost, Timolol \\
medication & under 65 on Travatoprost) & Bimatoprost & $30 \%$ \\
Percent failure & $12.5 \%$ & $0 \%$ & $20 \%$ \\
Surgery & $0 \%$ & $0 \%$ & $568.52(8 \%$ deviation - ALT), \\
Mean/expected cost, model & $\$ 527.75$ & $\$ 539.58$ & $562.88(4 \%$ deviation, SLT) \\
deviation from trial & & & \\
\hline
\end{tabular}



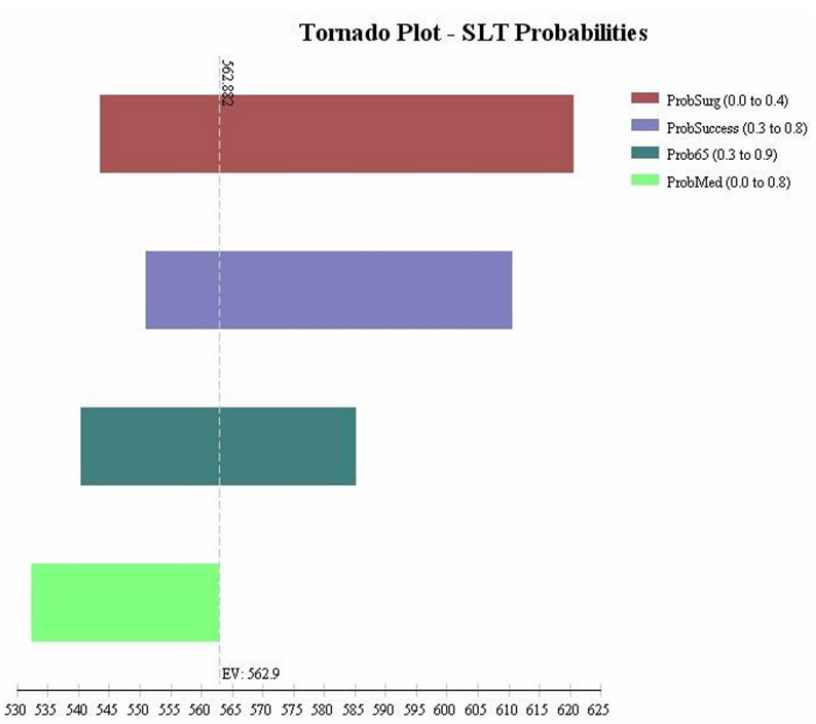

Figure 3. Tornado diagram - ministry perspective, base tree SLT

Nonetheless, the costs from trial and model agreed for the ministry perspective. If we accept Chumney's ${ }^{[20]}$ criterion of a $20 \%$ deviation in cost estimates as representing a policyimportant difference, for the ministry perspective our results are robust. This likely reflects the fact that labour was such a large component of cost and, crucially, that it varied minimally between patients. In this respect, physician costs operate almost as a fixed cost - minor variations around this fixed core of labour costs barely make a difference. This is in contrast to the situation in inpatient care or intensive care where labour is a large component of cost and it varies largely between patients. ${ }^{[21,22]}$ The stability of our clinical scenario is likely aided by the availability of relatively cheap generic drugs, thus differences in drug regimen failed to substantially alter cost estimates.

Our conclusion regarding the stabilizing influences of a large, fixed base of labour is bolstered by sensitivity analyses undertaken on the model. Changing those variables that increased labour requirements made a large impact on expected cost, while non-labour related variables had negligible effect on costs. Costs were insensitive to large changes in cohort age and percentage starting on medication. Even an older, highly medicated cohort failed to raise costs as much as increasing the rate of progression to surgery. This indicates that demographic makeup of the local patient population and physician-specific preferences regarding drug regimens likely have negligible effects for ministry costs.

Costs were more sensitive to probability of treatment failure and risk of progression to incisional surgery - this is likely due to their effects on expanding labour costs. High rates of surgery and failure, when combined, altered the price by more than $30 \%$ from the base model value and more than $40 \%$ from trial estimates.

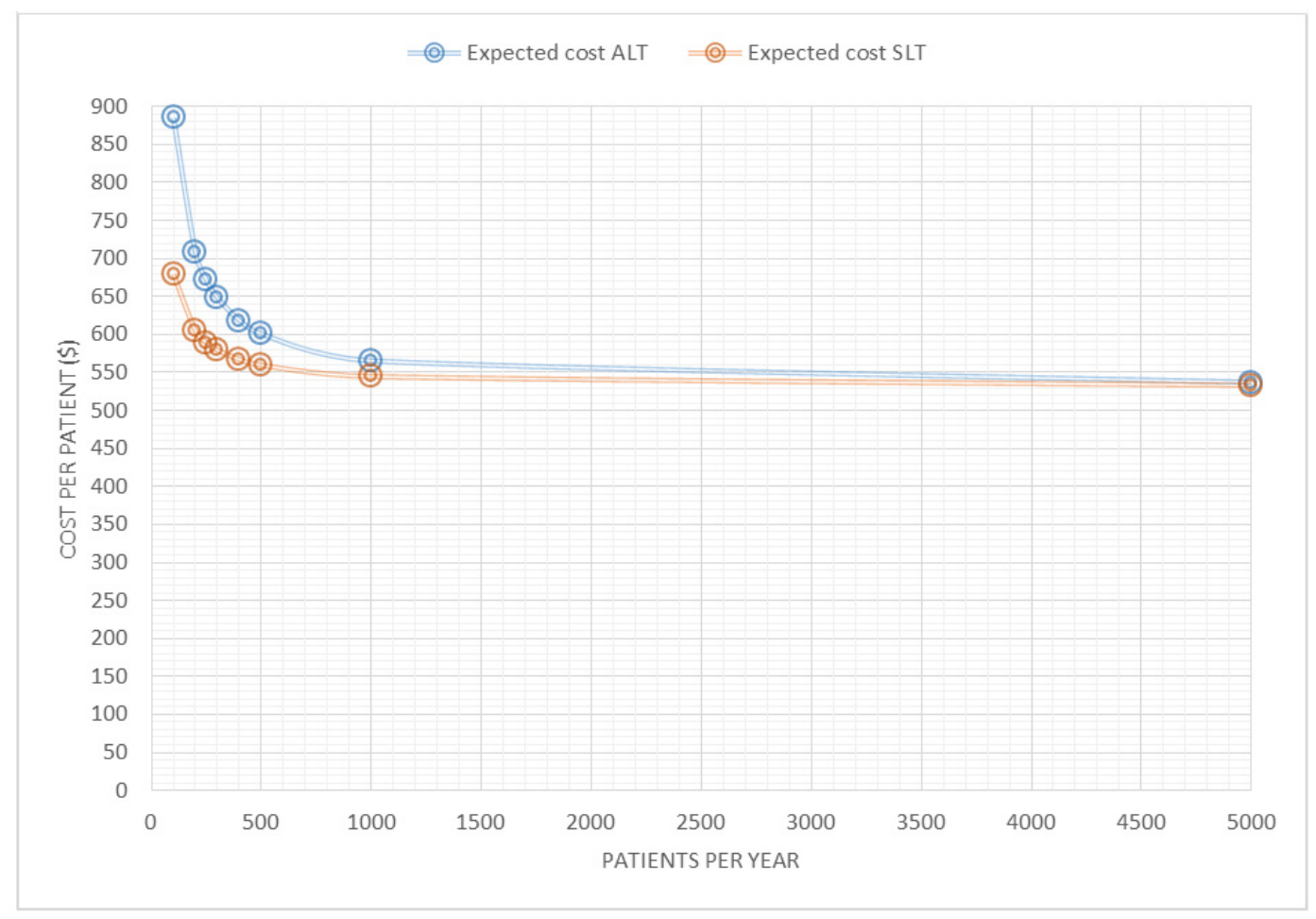

Figure 4. Effects of patient volume on expected cost - ALT and SLT 
Table 9. Patient time use and transportation characteristics

\begin{tabular}{lll}
\hline Characteristic & ALT $(\boldsymbol{n}=\mathbf{6})$ & SLT $(\boldsymbol{n}=\mathbf{7})$ \\
\hline Mode of transportation & $100 \%$ Car & $100 \%$ Car \\
Average one-way distance to SJHC $(\mathrm{km} \pm S D)$ & $38.7( \pm 39.5)$ & $38.6( \pm 45.8)$ \\
Average one-way time to SJHC $(\min \pm S D)$ & $37.75( \pm 34.52)$ & $35.4( \pm 35.65)$ \\
Employment status/alternate use of time & $4 / 6$ retired, 2/6 working & $5 / 7$ retired, 2/7 working \\
Accompanied by anybody? & $4 / 6$ (spouse) & $4 / 7(3$ spouse, 1 child $)$ \\
Time use of accompanying person & 3 retired, 1 working & 2 retired, 2 working \\
Informal caregiving & $0 \%$ & $0 \%$ \\
\hline
\end{tabular}

Table 10. Trial-based costs - societal perspective

\begin{tabular}{|c|c|c|c|c|}
\hline Cost category $^{\epsilon}$ & ALT $(n=8)$ & SLT $(n=8)$ & ALT \% of Total & SLT \% of Total \\
\hline Personnel total - total & $474.85(26.28)$ & $474.85(0)$ & $44.92 \%$ & $41.12 \%$ \\
\hline Capital & 36.56 & $30.92(0)$ & $3.46 \%$ & $2.68 \%$ \\
\hline Drugs & $40.64(46.42)$ & $51.84(89.53)$ & $3.84 \%$ & $4.49 \%$ \\
\hline Transportation & $251.64(278.49)$ & $185.14(257.09)$ & $23.80 \%$ & $16.03 \%$ \\
\hline Parking & $31(2.53)$ & $31(0)$ & $2.93 \%$ & $2.68 \%$ \\
\hline Patient time & $148.76(90.26)$ & $138.98(140.21)$ & $14.07 \%$ & $12.03 \%$ \\
\hline Accompanying person time & $73.72(75.96)$ & $241.98(476.32)$ & $6.97 \%$ & $20.96 \%$ \\
\hline Lost time, all persons & $222.49(136.37)$ & $380.96(608.03)$ & $21.04 \%$ & $32.99 \%$ \\
\hline Total & $1,057.18(383.2)$ & $1,154.71(805.23)$ & & \\
\hline
\end{tabular}

Note. ${ }^{\epsilon}$ All costs in 2014 Canadian dollars

Table 11. Model analysis of societal costs

\begin{tabular}{lll}
\hline & ALT & SLT \\
\hline Expected value & $\$ 1,146.64(8.5 \%$ deviation from trial) & $\$ 1,141.00(1.2 \%$ deviation from trial) \\
Univariate sensitivity analysis on FuTime $^{z}(1-4$ hours $)$ & $1,089.20,1,433.89$ & $1,083.56,1,428.25$ \\
\hline
\end{tabular}

Note. ${ }^{z}$ Average length of follow-up visit, increases may arise from increased transportation time, visit length or waiting time

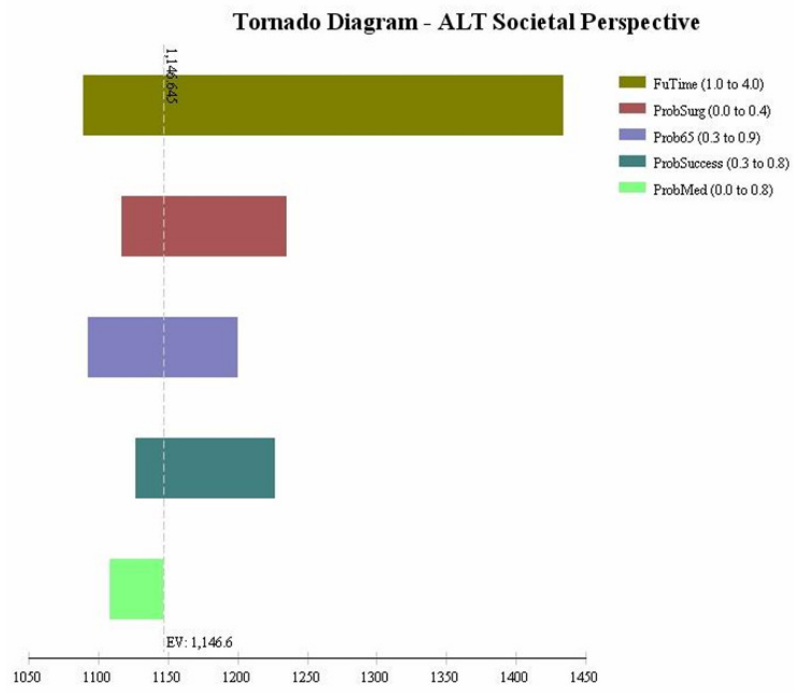

Figure 5. Tornado diagram - societal perspective, ALT

Adam et al. ${ }^{[5]}$ noted that the impact of capacity utilization on costs is understudied. The costs of delivering an intervention may differ based on patient load, all other factors held equal.
We address one aspect of capacity utilization, patient volume, on capital costs and final costs. We found that altering patient volume had a negligible effect on expected cost - a 10-fold annual increase in SLT patient visits results in less than $10 \%$ decrease in expected cost. Decreasing number of patients had a more pronounced effect in terms of increasing costs (see Figure 4). However, since these are tertiary clinics, we expect that such low patient volumes are unlikely - if patient volume was low enough, the clinic would presumably refer patients to a larger, tertiary clinic. The increased capital costs associated with low patient volume may be more relevant for rural settings or sparsely populated areas where such lowvolume institutions may nonetheless be obliged to purchase a laser.

Our findings regarding the large component of labour concur broadly with those of Oostenbrink et al. ${ }^{[23]}$ and KobeltNguyen ${ }^{[24]}$ who found outpatient encounters to be one of the largest components of cost for glaucoma treatment generally. These two studies also found a large contribution of drug costs, but it is worth noting that these studies were undertaken prior to generic production of many present day 
glaucoma medications.

To conclude, model and trial-based costs agree for the ministry perspective even though they differ in overall structure and parameter values. We speculate that the reason for this may be the large, invariant base of labour and the lack of high drug costs.

This study was a rare opportunity to validate the sorts of models commonly used in CEAs of glaucoma interventions, specifically with regards to costs. We found that for laser treatment in glaucoma, simpler model-based costing may be an acceptable, valid substitute for empirical, microcosting. Insofar as obtaining cost data by direct measurement is often tedious and expensive, our findings show that for at least some clinical scenarios we may be assured that easier methods suffice and that we may be free to use our time and resources towards ends other than costing.

\subsection{Indirect costs and the societal perspective}

The micro and model values for the societal perspective were as follows - ALT: \$1,057.18 vs. \$1,146.64 (8.5\%), SLT: $\$ 1,154.71$ vs. $\$ 1,141.00(1.2 \%)$. Firstly, indirect costs contribute substantially to total costs. Indirect and patient-borne costs are at least equal to direct costs of treatment, more than doubling costs from the societal perspective as compared to the ministry perspective. Secondly, while trial and model agree, there is sensitivity to assumptions considerably beyond that of the ministry case.

Costs from the societal perspective were much more variable than those from the ministry perspective. For SLT costs ranged between $\$ 630$ and close to $\$ 2,750$ from the societal perspective - from the ministry perspective costs for SLT ranged from $\$ 506$ and $\$ 750$. This differs from the findings of Sharma et al. ${ }^{[25]}$ who found a much narrower range of societal costs. This may reflect the less transportation intensive requirements of the clinics in Sharma et al.'s study. Indeed, transportation accounted for close to $20 \%$ of costs in our study - this was only considering motoring costs and not lost time due to transportation (which we factored into calculations of lost time). Indirect costs were evenly divided between transportation costs and the value of lost time. The large component of travel time was likely due to St. Joseph's Health Care (SJHC) being a major tertiary centre for Southwestern Ontario and environs. Indeed, several patients had to travel a one-way distance of over $100 \mathrm{~km}$. At a minimum of six visits per year, this requires over $1,200 \mathrm{~km}$ of travel for these patients. The majority of patients were retired, as befits glaucoma's higher prevalence in older persons. Consideration of retiree time is likely to become a significant consideration as the population ages. If an intervention rep-

Published by Sciedu Press resents a significant time burden then patients may be less likely to make all appointments on account of the inconvenience involved. If this contributes to disease progression, then costs to the healthcare system become commensurately higher as visual impairment increases. ${ }^{[26]}$

The tornado diagram in Figure 5 reflects the striking impact of assumed patient time loss relative to all other variables. As with the ministry perspective, probability of surgery and rates of success had more pronounced effects on the variations in cost than proportion medicated or average age (true even assuming that the majority of those over 65 were retired). However, even these are dwarfed by assumptions regarding the amount of time given to follow-up visits. This variable functions as a catch-all for any increased source of patient time commitment, whether in increased travel, increased appointment length or waiting time. Assuming that average follow-up visit time went from 1.5 hours (half hour travel each way, half hour appointment) to 2.5 hours expected costs rose by over $\$ 100$. Furthermore, given that we did not account for waiting times and the vicissitudes of weather (one patient noted that travel was significantly longer in winter), our estimates of societal costs are likely an underestimate.

\subsection{Limitations}

This research had several limitations. Firstly, we note the small sample size. Small sample sizes are not uncommon in microcosting studies (e.g. Kinsella's costing of a single case of neonatal ICU care, Venkatnaryan et al.'s costing of 8 babies for the same scenario). ${ }^{[27,28]}$ While we are uninterested in inferential endeavours in this study, ${ }^{[29]}$ our sample is small and we recognize this. We witnessed sensitivity to vicissitudes of the patient sample. In the model ALT was more expensive than SLT - this result was reversed in the trial. This is likely due to one outlier of an SLT patient who started the trial on 2 branded medications and happened to be over 65 - all other patients were either unmedicated or on generic drugs. Further, a single patient receiving SLT was accompanied by an employed family member who had to take a full day off on each accompanying visit and travelled over $100 \mathrm{~km}$ each direction, this accounts for the large standard deviations observed in accompanying patient time. It's possible that there is more homogeneity in the provision of trabeculoplasty than inpatient procedures (e.g. the range of costs for cardiac intervention in Clement et al.'s study ${ }^{[6]}$ spans two orders of magnitude). If that happens to the case, we obtain a large amount of information from a small number of observations. However, more observations are needed to assess homogeneity of costs in this intervention, and for simple credibility.

A second potential weakness was the limited horizon consid- 
ered in this study. The course of glaucoma is life long, ideally costing studies should reflect the lifetime course. ${ }^{[9]} \mathrm{We}$ demonstrated that model and trial agree over a short horizon, but important difference in resource use between alternatives is likely to occur downstream. Long-term effectiveness of SLT and its effects on downstream visual impairment need for medication and progression to surgery remain empirical problems. Further data on SLT's repeatability will provide a more rigorous basis for modelling.

Thirdly, other models are available. We assessed one model with sensitivity analyses on multiple parameters to represent a wide range of possible scenarios, and included an alternative model formulation to include the option for additional medication before surgery. However, the fact that multiple models are available for the same situation is to be expected. ${ }^{[30]}$ If our model is a good representation of the scenario and costs are robust to minor variations, then observed costs should be similar whether techs or nurses are used and regardless of patient volume, as well as with different local medication regimens and age composition - as such the performance of our model may be assessed against empirical studies in other settings. As noted by Cantor, ${ }^{[16]}$ the model is best thought of a conceptual framework with which to think about the clinical scenario and identify areas of high variability. Furthermore, the presence of multiple models may not be a problem, but rather a fact of life based on different models of healthcare delivery and characteristics of the health system. As noted by Koopmanschap et al., [31] costs are sensitive to a host of contextual factors such as local patterns of delivery, absolute and relative local prices and differences in cost accounting systems. The usefulness of any given model to a decision-maker is based on their needs.

\subsection{Future directions}

Less laborious modelling methods for assessing cost, as are common in glaucoma, provide a valid substitute for empirically derived microcosting for the ministry perspective, at least as pertains to laser therapy in glaucoma. The same is true of the societal perspective, with some caveats. The high patient time commitments in chronic disease as well as the impact of providing centre characteristics on transportation costs means that close attention must be paid to assumptions in the societal case as the results are more strongly influenced by assumptions regarding patient time commitments. Expansion of this question to other outpatient procedures in Ophthalmology will determine if modelling costing can be substituted for microcosting in a more general fashion.

\section{FUNDING SUPPORT}

Canadian Institute of Health Research (CIHR) Fund 201203INO and Ontario Graduate Student Scholarship.

\section{CONFLICTS OF INTEREST DisClosure}

There is no any conflict of interest with any authors.

\section{REFERENCES}

[1] Kagan DB, Gorfinkel NS, Hutnik CM. Mechanisms of selective laser trabeculoplasty: a review. Clin Experiment Ophthalmol. $2014 \mathrm{Sep}$; 42(7): 675-81. PMid: 24330092. https://doi.org/10.1111/ce 0.12281

[2] Kuper H, Jofre-Bonet M, Gilbert C. Economic evaluation for ophthalmologists. Ophthalmic Epidemiol. 2006 Dec; 13(6): 393-401. PMid: 17169853. https://doi.org/10.1080/09286580600760539

[3] Lipscomb J, Yabroff KR, Brown ML, et al. Health care costing: data, methods, current applications. Med Care. 2009 Jul; 47 (7 Suppl 1): S1-6. PMid: 19536004. https://doi.org/10.1097/MLR.0b01 3e3181a7e401

[4] Tan SS, Rutten FF, van Ineveld BM, et al. Comparing methodologies for the cost estimation of hospital services. Eur J Health Econ. 2009 Feb; 10(1): 39-45. PMid: 18340472. https://doi.org/10.100 7/s10198-008-0101-x

[5] Adam T, Koopmanschap MA, Evans DB. Cost-effectiveness analysis: can we reduce variability in costing methods? Int J Technol Assess Health Care. 2003 Spring; 19(2): 407-20. PMid: 12862197. https://doi.org/10.1017/S0266462303000369

[6] Clement FM, Ghali WA, Donaldson C, et al. The impact of using different costing methods on the results of an economic evaluation of cardiac care: microcosting vs gross-costing approaches.
Health Economics. 2009; 18(4): 377-388. PMid: 18615835. https: //doi.org/10.1002/hec.1363

[7] Frick KD. Micro-Costing Quantity Data Collection Methods. Med Care. 2009; 47(7 Suppl 1): S76-S81. PMid: 19536026. https: //doi.org/10.1097/MLR.0b013e31819bc064

[8] Gold MR, Siegel JE, Russell LB, et al. Cost-effectiveness in health and medicine. New York: Oxford University Press; 1996.

[9] Tan SS. Microcosting in economic evaluations: Issues of accuracy, feasibility, consistency and generalizability. PhD Thesis. Rotterdam: Erasmus Universiteit Rotterdam; 2009.

[10] Dakin H, Abangma G, Wordsworth S. What is the value of collecting detailed costing data in clinical trials? Trials. 2011; 12(Suppl 1): A42. https://doi.org/10.1186/1745-6215-12-S1-A42

[11] Drummond MF, Sculpher MJ, Torrance, et al. Methods for the Economic Evaluation of Health Care Programmes. Third Edition. Oxford, New York: Oxford University Press; 2005.

[12] Canadian Agency for Drugs and Technologies in Health. Guidelines for the economic evaluation of health technologies: Canada [ $3^{r d}$ Edition]. Ottawa: CADTH; 2006.

[13] Damji KF, Shah KC, Rock WJ, et al. Selective laser trabeculoplasty $\mathrm{v}$ argon laser trabeculoplasty: a prospective randomized clinical trial. Br J Ophthalmol. 1999; 83: 718-22. PMid: 10340983. https://doi.org/10.1136/bjo.83.6.718 
[14] Damji KF, Bovell AM, Hodge WG, et al. Selective Laser Trabeculoplasty vs Argon Laser Trabeculoplasty: Results from a 1 year RCT. Br J Ophthalmol. 2006; 90(12): 1490-4. PMid: 16899528. https://doi.org/10.1136/bjo.2006.098855

[15] McKee HD, Gupta MS, Ahad MA, et al. First-choice treatment preferences for primary open-angle glaucoma in the United Kingdom. Eye (Lond). 2005 Aug; 19(8): 923-4. PMid: 15375365. https://doi.org/10.1038/sj.eye.6701674

[16] Cantor LB, Katz LJ, Cheng JW, et al. Economic evaluation of medication, laser trabeculoplasty and filtering surgeries in treating patients with glaucoma in the US. Curr Med Res Opin. 2008; 24(10): 290518. PMid: 18768105. https://doi.org/10.1185/0300799080 2379996

[17] Cantor LB, Katz LJ, Cheng JW, et al. Pharmacoeconomic analysis of prostaglandin and prostamide therapy for patients with glaucoma or ocular hypertension. BMC Ophthal. 2007; 7(16).

[18] Finkler SA, Ward DM, Baker JJ. Essentials of cost accounting for health care organizations, Third edition. Sudbury, MA: Jones and Bartlett Learning; 2007.

[19] Barnett PG. An improved set of standards for finding cost for costeffectiveness analysis. Med Care. 2009 Jul; 47(7 Suppl 1): S828. PMid: 19536018. https://doi.org/10.1097/MLR.0b013e $31819 \mathrm{e} 1 \mathrm{f} 3 \mathrm{f}$

[20] Chumney EC. The effect of various costing approaches on the resulting cost effectiveness ratios and the policy significance of these variations. The University of North Carolina at Chapel Hill, ProQuest, UMI Dissertations Publishing. 2002. 3070833.

[21] Edbrooke D, Hibbert C, Ridley S, et al. The development of a method for comparative costing of individual intensive care units. The Intensive Care Working Group on Costing. Anaesthesia. 1999 Feb; 54(2): 110-20. PMid: 10215705. https://doi.org/10.1046/j.1365 $-2044.1999 .00650 . \mathrm{x}$

[22] Tan SS. Microcosting in economic evaluations: Issues of accuracy, feasibility, consistency and generalizability. PhD Thesis. Rotterdam: Erasmus Universiteit Rotterdam; 2009.

[23] Oostenbrink JB, Rutten-van Mölken MP, Sluyter-Opdenoordt TS. Resource use and costs of patients with glaucoma or ocular hyper- tension: a one-year study based on retrospective chart review in the Netherlands. J Glaucoma. 2001 Jun; 10(3): 184-91. PMid: 11442180. https://doi.org/10.1097/00061198-200106000-00007

[24] Kobelt-Nguyen G, Gerdtham UG, Alm A. Costs of treating primary open-angle glaucoma and ocular hypertension: a retrospective, observational two-year chart review of newly diagnosed patients in Sweden and the United States. J Glaucoma. 1998 Apr; 7(2): 95-104 PMid: 9559495. https ://doi.org/10.1097/00061198-19980 4000-00006

[25] Sharma A, Jofre-Bonet M, Panca M, et al. Hospital-based glaucoma clinics: what are the costs to patients? Eye (Lond). 2010 Jun; 24(6): 999-1005. http://dx.doi.org/10.4269/ajtmh.2 012.11-0090

[26] Rouland JF, Berdeaux G, Lafuma A. The economic burden of glaucoma and ocular hypertension: implications for patient management: a review. Drugs Aging. 2005; 22(4): 315-21. PMid: 15839720. https : //doi .org/10.2165/00002512-200522040-00004

[27] Kinsella S. Ten Lessons for Micro Costing in Health Economics. Available from: http://stephenkinsella.net/WordPress/wp - content/uploads/2008/07/tenlessons.pdf

[28] Venkatnarayan K, Sankar JM, Deorari A, et al. A micro-costing model of neonatal intensive care from a tertiary Indian unit: feasibility and implications for insurance. Indian Pediatr. 2014; 51: 215-7. PMid: 24736910. https://doi.org/10.1007/s13312-014-0376-1

[29] Claxton K. The irrelevance of inference: a decision-making approach to the stochastic evaluation of health care technologies. J Health Econ. 1999 Jun; 18(3): 341-64. https ://doi .org/10.1016/S0167-6 296 (98) 00039-3

[30] Simonella L, Canfell K. Development of a quality framework for models of cervical screening and its application to evaluations of the cost-effectiveness of HPV vaccination in developed countries. Vaccine. 2014 Aug 26. pii: S0264-410X(14)01171-2.

[31] Koopmanschap MA, Touw KC, Rutten FF. Analysis of costs and cost-effectiveness in multinational trials. Health Policy. 2001 Nov; 58(2): 175-86. https://doi.org/10.1016/S0168-8510(01)0 0142-7 